Published online 2017 April 13.

Abstract

\title{
The Importance of Diffusion Weighted Imaging in Breast MRI
}

\author{
Maryam Noori, ${ }^{1}{ }^{*}$ Bahareh Siahlou, ${ }^{1}$ Hamidreza Salighehrad, ${ }^{1}$ Anahita Fathi, ${ }^{1}$ and Mohammad Fathi ${ }^{1}$ \\ ${ }^{1} \mathrm{MD}$, Radiologist, Paytakht \\ "Corresponding author: Maryam Noori, MD, Radiologist, Paytakht. E-mail: m_noori5005@yahoo.com
}

Received 2016 December 21; Accepted 2017 February 08.

\begin{abstract}
Objectives: The aim of this study was to evaluate the value of diffusion weighted imaging in Diffusion weighted imaging in distinguishing between in benign and malignant breast lesion

Methods: There were 37 female patients with 47 lesions. Sixty seven female subjectd (40 mean age ), age ranges 17-69 , with histopathologically proven breast lesions underwent DWI of breasts with a single shot echo planar imaging (EPI)sequence .the computed mean apparent diffusion cofficients (ADCs) of the breasts lesion and cell density were then correlated.

Results: The ADC varied substantially between benign breast lesions $((1.52 \pm 0.26) \times 10-3 \mathrm{~mm} 2 /$ second $)$. And malignant breast lesions $((0.94 \pm 0.21) \times 10-3 \mathrm{~mm} 2$ / second $)$. The AUC with ROC analysis was 0.896 and the threshold for ADC was $1.17 \times 10-3 \mathrm{~mm} 2$ /second with a sensitivity and specificity of $90 \%$ and $85 \%$, respectively. The mean ADC of malignant breast lesions was statistically lower for benign lesions (P value less than 0.01)

Conclusions: The ADC would be a effective parameter in distinguishing between malignant and benign breast lesions.
\end{abstract}

This is an abstract presented in the 33rd Iranian congress of radiology (ICR) and the 15th congress of Iranian radiographic science association (IRSA)

Copyright (c) 2017, Tehran University of Medical Sciences and Iranian Society of Radiology. This is an open-access article distributed under the terms of the Creative Commons Attribution-NonCommercial 4.0 International License (http://creativecommons.org/licenses/by-nc/4.0/) which permits copy and redistribute the material just in noncommercial usages, provided the original work is properly cited. 